\title{
FETO-MATERNAL OUTCOME OF VAGINAL DELIVERY AND CAESAREAN SECTION IN ECLAMPTIC PATIENTS
}

\author{
BEGUM N ${ }^{1}$, JAHAN $\mathrm{S}^{2}$, GANGULY $\mathrm{S}^{3}$, ANWAR BR ${ }^{4}$
}

\begin{abstract}
:
Eclampsia is a major cause of maternal morbidity and mortality. It is largely a preventable disease provided the pregnant women get regular antenatal care. It's incidence in Bangladesh is still high. Lack of health education, low socioeconomic condition, lack of adequate facilities to deal with the emergency situation, inadequate referral and transfer system are important contributing factors of consideration. In many peripheral centers, facilities to deal with such a complicated patient are absent. This prospective study was conducted in the eclampsia ward in the Department of Obstetrics and Gynaecology, Dhaka Medical College Hospital, Dhaka, from July to December, 2004. Our aim was to identify the better mode of termination of pregnancy in eclamptic patients. Hundred antenatal eclamptic patients were purposively selected for the study. Eclampsia is a disease of relatively younger age group. Out of 100 patients, 53 percent were $<20$ years of age, 42 percent patients were primigravida and 67 percent patients were from low socioeconomic condition. 72 percent patients of vaginal delivery group and 60 percent patients of caesarean section group had no antenatal care (ANC). Maternal morbidity was more in vaginal delivery group (56\%) than in caesarean section group (36\%). Maternal mortality rate was $4 \%$ in both the groups. Perinatal mortality was higher in vaginal delivery (36\%) than in caesarean section group (22\%).
\end{abstract}

Key words: Eclampsia, vaginal delivery, Caesarean section operation.

J Dhaka Med Coll. 2015; 24(2) : 92-98.

\section{Introduction:}

Eclampsia is a leading cause of maternal morbidity and mortality worldwide. Globally it contributes to $12 \%$ of maternal mortality ${ }^{1}$. In Bangladesh, eclampsia is one of the most common cause of maternal and perinatal morbidity and mortality. In spite of different preventive approaches to improve the obstetric care in Bangladesh, eclampsia still contributes to $20 \%$ of maternal mortality ${ }^{2}$. Eclampsia is the occurrence of one or more convulsions superimposed on preeclampsia ${ }^{3}$. Eclampsia occurs in patients with preeclampsia who had failed to receive regular antenatal care or in whom a relative sudden increase in blood pressure or the appearance of proteinuria has been overlooked. The onset of eclampsia is usually insidious and the patients often has minimal or no symptoms until she presents with eclamptic fits. Standardized care package for preeclampsia over delivery with proven intervention reduce the rate of eclampsia ${ }^{4}$. Proper antenatal care and management of complications has reduced the adverse effects of eclampsia on mother and her child in developed countries.

Eclampsia is a multisystem disorder affecting almost all organs of the body with endothelial cell damage central to its symptomatology. The first goal of management of eclampsia is control of convulsions and stabilization of the patients' cardiovascular status. Magnesium sulphate is the most effective and safe anticonvulsant used for control of convulsions.

1. Dr. Nazneen Begum, Assistant Professor, Department of Obstetrics \& Gynaecology, Dhaka Medical College Hospital, Dhaka.

2. Dr. Shawkat Jahan, Assistant Professor, Department of Obstetrics \& Gynaecology, Dhaka Medical College Hospital, Dhaka.

3. Dr. Shikha Ganguly, Associate Professor, Department of Obstetrics \& Gynaecology, Dhaka Medical College Hospital, Dhaka.

4. Begum Rokeya Anwar, Assistant Professor, Department of Obstetrics \& Gynaecology, National Institute for Cancer Research \& Hospital (NICRH), Dhaka.

Correspondence: Dr. Nazneen Begum, Assistant Professor, Department of Obstetrics \& Gynaecology, Dhaka Medical College Hospital, Dhaka. E-mail: begumnazneen80@gmail.com 
Hypertention is controlled by intravenous hydralazine or labetalol followed by oral nifedipine or atenolol. Regardless of the gestational age pregnancy is terminated immediately either vaginally or by caesarean section. If induction delivery interval is more, there is more chance of recurrence of convulsion. So caesarean section is preferred in many cases, especially when the fetus is alive and induction delivery interval is suspected to be prolonged. But now with the advent of effective anticonvulsant ( magnesium sulphate) and effective cervical ripening agent (misoprostol) vaginal delivery is preferred in many cases particularly when fetus is dead or in a moribund condition not likely to survive to avoid complications of caesarean section.

\section{Materials and Methods:}

This was a cross sectional analytical study taking 100 purposively selected antenatal eclamptic patients. The study was conducted in the Eclampsia ward of Department of Obstetrics and Gynaecology, Dhaka Medical College Hospital, Dhaka, over a period of July to December, 2004

The aim of the study was to identify the better mode of termination of pregnancy in eclampsia patients.

All the patients were given a comprehensive explanation of the study. A questionnaire was designed encompassing all relevant clinical information. After taking a very careful history, a thorough physical examination was performed. Immediately after that, urine was tested for protein by heat coagulation method in the eclampsia ward and cases were diagnosed. Convulsion was controlled in all cases by magnesium sulphate. After inital management when patient's condition was stable, decision for termination of pregnancy was taken, and the mode of delivery was planned considering the adequacy of pelvis, condition of the cervix, gravidity and gestational age . Patients who needed termination of pregnancy by caesarean section were operated under spinal anaesthesia. Many of the patients who were selected for vaginal delivery were managed by assisted vaginal delivery (forceps / ventouse) to expedite the duration of second stage of labour. Patients were excluded from either group, when eclampsia was complicated with acute pulmonary oedema, renal failure, shock, coagulation failure on admission, obstetrical factors, which needed emergency caesarean section, e.g. cephalopelivic disproportion, placenta praevia, malpresentation and obstructed labour. Caesarean section done for prolonged labour, failed induction, anticipating prolonged induction delivery interval, fetal distress were included in the study. High dependency care was provided in the eclampsia ward as long as the patients demanded.

Maternal outcome measures were maternal mortality and morbidity eg, pulmonary edema, cerebrovascular accident (CVA), renal failure, obstetric shock, abuptio placenta, and postpartum hemorrhage (PPH) . Parameters for fetal and neonatal outcomes were birth weight, APGAR score, live or still births and any complication.

Collected data were analyzed by using computer based software, Statistical Package for Social Science (SPSS). Quantitative variables were analysed using Student's t-test and qualitative variables using the Chi-square test. $\mathrm{P}<0.05$ was considered to indicate a statistically significant result.

\section{Results:}

Table-I shows that the mean age of patients of vaginal delivery group was $22.38 \pm 4.44$ years and Caesarean section group was 22.94 4.93years. The mean duration of pregnancy in vaginal delivery group was $36.14 \pm 3.40$ weeks and in Caesarean section group was $36.26 \pm 3.02$ weeks. The mean number of convulsions before hospitalization in vaginal delivery group was 5.10 times and in caesarean section group was 5.06 times. The mean interval between first convulsion and hospitalization was 6.14 hours in vaginal delivery group and in caesarean section group was 5.40 hours. The mean systolic blood pressure was $151.10 \mathrm{mmHg}$ in vaginal delivery group and in caesarean section group was $154.20 \mathrm{mmHg}$. The mean diastolic blood pressure was $105.10 \mathrm{mmHg}$ in vaginal delivery group and in caesarean section group was $105.40 \mathrm{mmHg}$. Study 
population showed that most of the eclamptic patients (54\%) patients of vaginal delivery group and $52 \%$ patients of caesarean section group) were below 20 years of age. Most of the patients $(46 \%)$ were primigravida. Most of the patients i.e. $70 \%$ of the patients of vaginal delivery group and $64 \%$ patients of caesarean section group) were from low socioeconomic status. Maximum eclamptia patients i.e. $72 \%$ patients of vaginal delivery group and 60\% patients of caesarean section group, received no antenatal care.

Most of the patients had mild proteinuria, as shown in the table-II, $48 \%$ of the patients of vaginal delivery group and $54 \%$ patients of caesarean section group. Only $12 \%$ of vaginal delivery group had severe proteinuria. Table.III shows that maternal morbidity, pulmonary oedema (22\%), CVA (12\%) and obstetric shock $(6 \%)$ were more in vaginal delivery group. Maternal mortality due to eclampsia was $4 \%$. Out of two death of vaginal delivery group, 1 pateint died of pulmonary oedema and 1 patient died of cerebrovascular accident. In caesarean section group, 2 patients died of pulmonary oedema. Mean birth weight of babies, as shown in the table-IV, in vaginal delivery group was $2.27 \mathrm{~kg}$ and in Caesarean section group was $2.15 \mathrm{~kg}$. 1-minute APGAR score is better in caesarean section group (6.28) than vaginal delivery group (5.69). Fig. 1 shows that perinatal mortality was higher in vaginal delivery group(36\%) compared to caesarean caesarean section group (22\%). $75 \%$ of neonatal death was due to prematurity and $25 \%$ was due to asphyxia.

Table-I

Comparison of patient characteristics between two study groups

\begin{tabular}{|c|c|c|c|}
\hline Parameters & $\begin{array}{l}\text { Vaginal delivery } \\
(\mathrm{n}=50) \text { No. } /(\%)\end{array}$ & $\begin{array}{l}\text { Caesarean section } \\
(\mathrm{n}=50) \text { No. } /(\%)\end{array}$ & $\mathrm{P}$ value \\
\hline Age (Years) Mean \pm SD & $22.38 \pm 4.44$ & $22.948 \pm 4.94$ & ${ }^{\mathrm{a}} 0.552^{\mathrm{ns}}$ \\
\hline Range & $27-35$ & $17-37$ & \\
\hline \multicolumn{4}{|l|}{ Parity } \\
\hline 0 & $19(38.0)$ & $23(46.0)$ & \\
\hline 1 & $24(48.0)$ & $18(36.0)$ & ${ }^{\mathrm{b}} 0.272^{\mathrm{NS}}$ \\
\hline 2 or more & $7(14.0)$ & $9(18.0)$ & \\
\hline \multirow{2}{*}{\multicolumn{4}{|c|}{$\begin{array}{l}\text { Duration of pregnancy } \\
\text { (Weeks) }\end{array}$}} \\
\hline & & & \\
\hline Mean \pm SD & $36.14 \pm 3.40$ & $36.26 \pm 3.02$ & ${ }^{\mathrm{a}} 0.852^{\mathrm{NS}}$ \\
\hline Range & $26-40$ & $28-42$ & \\
\hline \multicolumn{4}{|l|}{ Antenatal care } \\
\hline Regular/irregular & $14(28.0)$ & $20(40.0)$ & ${ }^{\mathrm{b}} 0.146^{\mathrm{NS}}$ \\
\hline None & $36(72.0)$ & $30(60.0)$ & \\
\hline \multicolumn{4}{|l|}{ Socioeconomic status } \\
\hline Low & $35(70.0)$ & $32(64.0)$ & \\
\hline Middle & $14(28.0)$ & $17(34.0)$ & ${ }^{\mathrm{b}} 0.489^{\mathrm{NS}}$ \\
\hline Upper Middle & $1(2.0)$ & $1(2.0)$ & \\
\hline
\end{tabular}

aUnpaired Student's ' $\mathrm{t}$ ' test

${ }^{\mathrm{b}}$ Chi-Squate test

NS Not significant 
Table-II

Comparison of different maternal parameters between the two study groups on admission

\begin{tabular}{|c|c|c|c|}
\hline Parameters & $\begin{array}{l}\text { Vaginal delivery } \\
(\mathrm{n}=50)\end{array}$ & $\begin{array}{l}\text { Caesarean section } \\
(\mathrm{n}=50)\end{array}$ & $\mathrm{P}$ value \\
\hline \multicolumn{4}{|l|}{ Number of convulsions } \\
\hline Before hospitalization & & & ${ }^{\mathrm{a}} 0.960^{\mathrm{NS}}$ \\
\hline Mean \pm SD & $5.10 \pm 3.82$ & $5.06 \pm 4.19$ & \\
\hline Range & $1-16$ & $1-16$ & \\
\hline \multicolumn{4}{|c|}{$\begin{array}{l}\text { Interval between first convulsion } \\
\text { and hospitalization (hours) }\end{array}$} \\
\hline Mean \pm SD & $6.14 \pm 4.69$ & $5.40 \pm 5.34$ & $\mathrm{a} 0.462^{\mathrm{NS}}$ \\
\hline Range & $0.50-24.00$ & $0.50-24.00$ & \\
\hline \multicolumn{4}{|c|}{ Diastolic blood pressure (mmHg) } \\
\hline Mean \pm SD & $105.10 \pm 14.45$ & $105.40 \pm 14.67$ & ${ }^{\mathrm{a}} 0.918^{\mathrm{NS}}$ \\
\hline Range & $110-215$ & $95-220$ & \\
\hline \multicolumn{4}{|l|}{ Urinary albumin } \\
\hline Trace & $3(6.0)$ & $5(10.0)$ & \\
\hline Mild & $24(48.0)$ & $27(54.0)$ & \\
\hline Moderate & $17(34.0)$ & $18(36.0)$ & ${ }^{\mathrm{b}} 0.119^{\mathrm{NS}}$ \\
\hline Severe & $6(12.0)$ & 0 & \\
\hline
\end{tabular}

aUnpaired Student's ' $t$ ' test

${ }^{\mathrm{b}} \mathrm{Chi}$-Squate test

NS Not significant

Table-III

Maternal Outcome $(N=100)$

\begin{tabular}{llll}
\hline Variables & $\begin{array}{l}\text { Vaginal delivery } \\
(\mathrm{n}=50)(\%)\end{array}$ & $\begin{array}{l}(\%) \text { Caesarean } \\
(\mathrm{n}=50)\end{array}$ & $\begin{array}{l}\text { section } \\
\text { value }\end{array}$ \\
\hline $\begin{array}{l}\text { Maternal death } \\
\text { Maternal morbidity }\end{array}$ & $2(4.0$ & $2(4.0)$ & $0.691^{\text {NS }}$ \\
$\begin{array}{l}\text { Obstetric shock } \\
\text { Cerebrovascular }\end{array}$ & $11(22.0)$ & $9(18.0)$ & \\
Accident(CVA) & $3(6.0$ & 0 & \\
Wound Infection & $6(12)$ & $1(2.0)$ & \\
Postpartum & & & \\
Haemorrhage & $1(2.0$ & $5(10.0)$ & \\
Renal failure & & & \\
Abruptio Placenta & $4(8.0)$ & $2(4.0)$ & \\
Hepatic failure & $1(2.0)$ & 0 & \\
Puerperal psychosis & $1(2.0)$ & 0 & \\
Total Morbidity & 0 & $1(2.0)$ & \\
\hline
\end{tabular}

${ }^{\mathrm{a}}$ Fisher exact test

NS Not significant 
Table-IV

Comparison of different neonatal parameters between the two study groups

\begin{tabular}{|c|c|c|c|}
\hline Parameters & $\begin{array}{l}\text { Vaginal delivery } \\
(\mathrm{n}=36)\end{array}$ & $\begin{array}{l}\text { Caesarean section } \\
(\mathrm{n}=43)\end{array}$ & $P$ value \\
\hline Birth weight of baby (kg) & $2.27 \pm 0.45$ & $2.15 \pm 0.56$ & $0.311^{\mathrm{NS}}$ \\
\hline Mean \pm SD & $1.30-3.00$ & $0.90-3.30$ & \\
\hline \multicolumn{4}{|l|}{ Range } \\
\hline \multicolumn{4}{|l|}{ 1-minute Apgar score } \\
\hline Mean \pm SD & $5.69 \pm 1.23$ & $6.28 \pm 1.55$ & $0.071^{\mathrm{NS}}$ \\
\hline Range & & & $3-83-8$ \\
\hline \multicolumn{4}{|l|}{ 5-minute Apgar score } \\
\hline Mean \pm SD & $8.06 \pm 1.35$ & $8.30 \pm 1.46$ & $0.441^{\mathrm{NS}}$ \\
\hline Range & $4-10$ & $5-10$ & \\
\hline
\end{tabular}

aUnpaired Student's ' $t$ ' test

NS Not significant

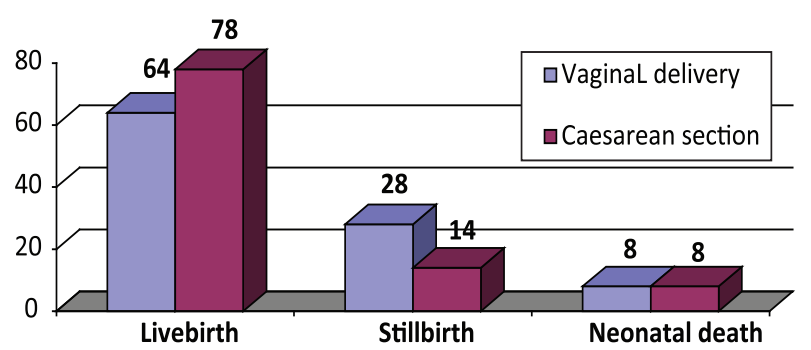

Fig.-1: Perinatal outcome in vaginal delivery and caesarean section groups

\section{Discussion:}

Eclampsia is an important cause of both maternal and fetal morbidity and mortality in pregnant women. The treatment of preeclampsia is important in the reduction of morbidity and mortality ${ }^{5}$, the high perinatal mortality associated with this disorder has fallen significantly ${ }^{6}$. In Previous studies, it was concluded that women with eclampsia particularly if they are more than 30-35 years old, overweight, and with previous history of hypertension, must be carefully managed by expert physicians in order to decrease the complications ${ }^{7}$. It is seen more often in primigravida women than in multiparous women. Recent epidemiologic studies suggest that multiparous women with different partners have a higher risk for preeclampsia than multiparous woman with the same partner, perhaps because of a protective effect of repeated exposure to specific antigens ${ }^{8}$. In this study, most of the patients (53\%) were $<20$ years of age. Rouf et al. ${ }^{9}$ have shown that maximum number of eclampsia patients were between 15 and 25 years of age. Khatun et al. ${ }^{10}$ in her study has found that $55 \%$ of the patients were within the age range of 15 to 20 years, reflecting the fact that this is a disease of relatively younger age group. This study shows most $(46 \%)$ of the patients were primigravida. Almost similar results have been shown in other studies of this country ${ }^{9-11}$. Here $70 \%$ of the patients of vaginal delivery group and 64\% of caesarean section were from low socioeconomic status. Study of Alam ${ }^{11}$ and Chowdhury ${ }^{12}$ have shown comparable results, e.g. Chowdhury ${ }^{12}$ in her study has shown that 95\% of the patients were from low socioeconomic condition. Many patients of vaginal delivery group $(72 \%)$ and caesarean section group $(60 \%)$ could not avail the opportunity of antenatal care in this study. Alam ${ }^{11}$ in her study has shown that 29\% patients received no ANC and 53.3\% irregular ANC. In this study most of the patients of vaginal delivery group $(48 \%)$ and caesarean section group (54\%) had mild proteinuria. Previous studies also showed higher percent of mild to moderate proteinuria $(68 \%)^{12}$.

In this study, maternal complications were more in vaginal delivery group (Table III), 
pulmonary oedema (22\%), CVA (12\%) and obstetric shock $(6 \%)$ were more in vaginal delivery group. Another study also shows higher percentage of pulmonary oedema $(28 \%)$ and CVA $(10 \%)$ in vaginal delivery group ${ }^{12}$. Two percent patients of vaginal delivery group developed renal failure. In this study, wound infection was higher $(10 \%)$ in caesarean section group. Meternal death in vaginal delivery group and caesarean section group was same (4\%). Out of 2 meternal deaths in vaginal delivery group, one was due to pulmonary oedema and one was due to cerebrovascular accident. In caesarean section group, two maternal deaths were due to pulmonary oedema. Almost similar result was found in another study ${ }^{12}$. Witlin et al. ${ }^{13}$ found that operative delivery by cesarean section in pregnancies with eclampsia reduced complications to the fetus as well as the mother. Most of the babies had low birth weight, mean birth weight of babies in vaginal delivery groups was $2.27 \mathrm{~kg}$ and in Caesarean section group was $2.15 \mathrm{~kg}$. Alam ${ }^{11}$ showed in her study that $75 \%$ of the babies had weight $<2.5 \mathrm{~kg}$. 1-minute Apgar score is better in caesarean section group $(6.28 \%)$ than vaginal delivery group (5.64\%). Almost similar results have been shown in other studies ${ }^{11,12}$. Table shows that perinatal mortality was higher in vaginal delivery group (36\%) compared to caesarean section group (22\%). Other studies showed low perinatal mortality in caesarean section group $(26 \%)$ than in vaginal delivery group ${ }^{12}$. Seventy five percent of neonatal death was due to prematurity and $25 \%$ was due to asphyxia. Shahabuddin et al. ${ }^{14}$ in their study showed asphyxia and prematurity as bigger cause of prenatal loss (92\%). Alam ${ }^{6}$ in her study showed prematurity as the most common cause of perinatal death $(53.65 \%)$. In this study, the patients undergoing cesarean section showed a better maternal outcome with fewer maternal complications than that of vaginal delivery group. Regarding fetal outcome, the number of stillbirth baby was less in the cesarean section group than that in the vaginal delivery group.

\section{Conclusion:}

Eclampsia is one of the major causes of maternal and perinatal mortality, particularly in developing countries. A rational therapy for general management including management of hypertension and convulsion has been established in our setup, but the obstetric management is the area, where controversy still exists. As we do not have adequate facilities for intranatal monitoring, Caesarean section is chosen in many cases considering that these patients and fetus may not tolerate the stress of labour. However, there are studies showing that, in selected patients, vaginal delivery may be better than caesarean section. This study has reflected the fact that overall maternal and perinatal mortality and morbidity is better in Caesarean section group. As this is a small sample study, study with larger sample is recommended to make a definitive conclusion.

\section{References:}

1. World Health Organization. RHR, Making pregnancy safer. Geneva: WHO; 2007.

2. Bangladesh Maternal Mortality and Health Care Survey (BMMS) 2010. Dhaka: ICDDRB \& NIPORT; 2011 .

3. Alttnan D, Cattoli G, Duley L, Fattel B, Moodly J, Neilson $\mathrm{J}$, et al. Women with preeclampsia and their babies benifited from magnesium sulphate? The Magpie Trial: randomized placebo-controlled trial. Lancet 2002; 359: 1877-90.

4. Tuffnell DJ, Jankowicz D, Lindow SW, Lyons G, Mason GC, Russel IF, et al. Outcomes of severe preeclampsia/eclampsia in Yorkshire 1999/2003. BJOG 2005, 112: 875-80.

5. Chung NA, Beevers DG, Lip GY. Management of hypertension in pregnancy. Am J Cardiovasc Drugs 2001; 1: 253-62.

6. Kurkinen-Raty M, Koivisto M, Jouppila P. Preterm delivery for maternal or fetal indications: maternal morbidity, neonatal outcome and late sequelae in infants. BJOG 2000; 107: 648-55.

7. Alvarez Navascues R, Marin R. Severe maternal complications associated with pre-eclampsia: an almost forgotten pathology? [In Spanish] [Abstract]. Nefrologia 2001; 21: 565-73.

8. Pridjian G, Puschett JB. Preeclampsia. Part 1: Clinical and pathophysiologic considerations. Obstet Gynecol Surv 2002; 57: 598-618. 
9. Rouf S, Shamsuddin L, Khan JH. Magnesium sulphate versus diazepam in the management of eclampsia. Bangladesh J Obstet Gynaecol 1996; 11: $1-14$.

10. Khatun S, Nilufar S. Bhuiyan AB, Begum K. Perinatal outcome in eclampsia. Bangladesh $\mathrm{J}$ Obstet Gynaecol 1994; 9: 53-63.

11. Alam PI. A study of perinatal outcome in eclampsia in Dhaka Medical College Hospital [dissertation]. Dhaka: Bangladesh College of Physicians \& Surgeons, 2002.
12. Chowdhury ML. Role of Caesarean section in improving fetomaternal outcome esclampsia [dissertation]. Dhaka: Bangladesh College of Physicians \& Surgeons; 1998.

13. Witlin AG, Saade GR, Mattar F, Sibai BM. Predictors ofneonatal outcome in women with severe preeclampsia or eclampsia between 24 and 33 weeks' gestation. Am J Obstet Gynecol 2000; 182: $607-11$.

14. Shahabuddin AKM, Hashnat M, Hamid T, Rahman AF. Perinatal outcome of eclampsia in a Medical College Hospital. Bangladesh J Child Health 1996; 20: 8-14. 